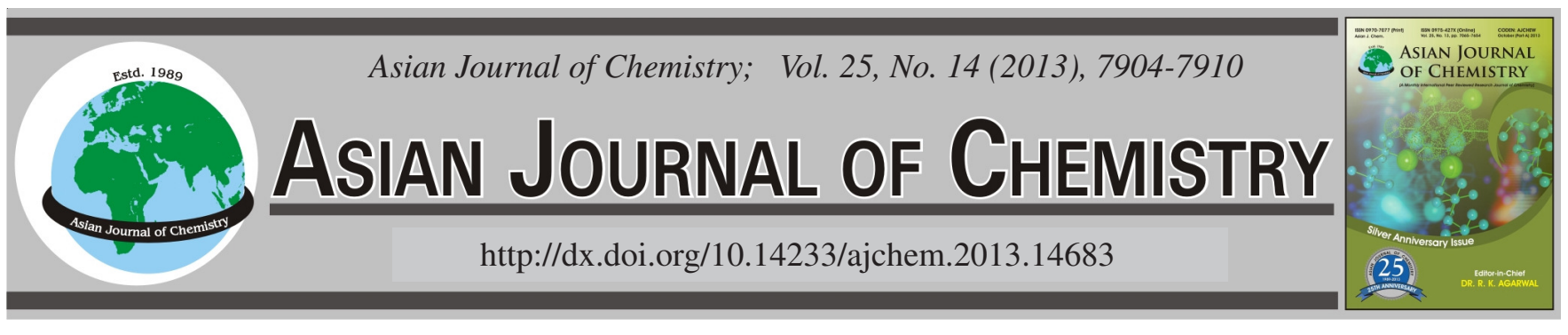

\title{
Comparison of Molecular Structures with DFT and HF of Isoxazoline and Isoxazolidine
}

\author{
Y.S. KARA ${ }^{1, *}$ and S.G. SAGDINC ${ }^{2}$
}

\begin{abstract}
${ }^{1}$ Department of Chemistry, Science and Art Faculty, Kocaeli University, Umuttepe Campus, 41380 Kocaeli, Turkey
${ }^{2}$ Department of Physics, Science and Art Faculty, Kocaeli University, Umuttepe Campus, 41380 Kocaeli, Turkey

*Corresponding author: Fax: +90 262 3032003; Tel: +90 262 3032057; E-mail: kara69@ gmail.com
\end{abstract}

\begin{abstract}
Quantum chemical methods [density functional theory (DFT), ab initio (HF) and semi emperical methods] have given to be very important information about the molecular structure in addition to elucidating the electronic structure and reactivity. They have also proved to be a useful tool for studying inhibition mechanisms. In the present study, quantum chemical calculations using the density functional theory and ab initio (HF) methods have been performed on three isoxazoline and three isoxazolidine derivatives used as corrosion inhibitors to found the relationship between molecular structure and their inhibition efficiencies. The corresponding structures have been optimized and the highest occupied molecular orbital energy $\left(\mathrm{E}_{\text {номо }}\right)$, the lowest unoccupied molecular orbital energy $\left(\mathrm{E}_{\mathrm{Lumo}}\right)$, energy gap $(\Delta \mathrm{E})$, electronegativity $(\chi)$, hardness $(\eta)$, softness $(\sigma)$ and the fraction of electrons transferred from the inhibitor molecule to the metal surface $(\Delta \mathrm{N})$ have been calculated using the DFT/B3LYP and HF methods with the 6-31G(d,p) basis set.
\end{abstract}

Key Words: Corrosion inhibition, DFT, HF, Quantum chemical calculation, Isoxazoline derivatives, Isoxazolidine derivatives.

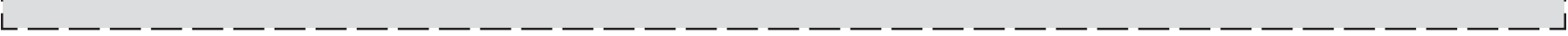

\section{INTRODUCTION}

Heterocycles are an important class of compounds not only due to their natural abundance but also because of their similarities with isoxazoline and isoxazolidine mainly due to their pharmacological activity ${ }^{1}$. The isoxazoline derivatives have been reported to possess a variety of significant and diverse pharmacological activities such as antibacterial, anti-candida activity, antifungal, HIV-RT activity ${ }^{2-6}$. Similarly, the isoxazolidine derivatives have been published to many pharmacological activities such as antibacterial, antiretroviral drug, hypoglycemic agents, anti-inflammatory, anti-tubercular, anticancer ${ }^{7-12}$. They have been also reported earlier as corrosion inhibitors ${ }^{13-14}$.

Recently Yildirim et al. ${ }^{15}$ have been investigated experimentally that isoxazoline and isoxazolidine derivatives showed inhibitive properties for iron and its alloys in $2 \mathrm{M} \mathrm{HCl}$ solutions $20 \mathrm{~h}$ at room temperature. In our previous study, we have performed quantum chemical calculations on acetamides and isoxazolidine derivatives, using the DFT and HF methods ${ }^{16}$.

The relationships between the structural parameters and corrosion inhibition of isoxazoline derivatives have not been studied yet. Therefore, the aim of this study is to present theoretical study on electronic and molecular structure of three isoxazoline 5-octylsulfanylmethyl-3-phenyl-4,5-dihydroisoxazol (OSPI), [1-(3-phenyl-4,5-dihydro-isoxazol-5-yl)nonan-2-ol (PINO), 9-(3-phenyl-4,5-dihydro-isoxazol-5-yl)nonanoic acid 2-[2-(methoxy-ethoxy)-ethoxy]-ethyl ester
(PINEE)] used as inhibitors and to compare the relationship between some quantum chemical parameters/descriptors from the structures of isoxazoline and isoxazolidine [5-octylsulfanylmethyl-2,3-diphenyl-isoxazolidine (OSDPI), 1-(2,3)diphenyl-isoxazolidin-5yl)nonan-2-ol (DPINO), 9-(2,3-diphenylisoxazolidin-5-yl)nonanoic acid 2-[2-(2-methoxy-ethoxy)ethoxy]ethyl ester (DPINEE)] and inhibition efficiencies (Table-1).

\section{EXPERIMENTAL}

The geometry pre-optimizations of the molecules studied have been carried out by applying the molecular-mechanics method with the MM+ force field using the HyperChem-7.5 software ${ }^{17}$. Thereafter, the optimized equilibrium structures of molecules have been calculated at the B3LYP and HF methods 6-31G(d, p) basis set. The corresponding goemetries have been optimized without any geometry constraints for full geometry optimizations. The molecules have been built with the Gauss View 3.0 visualization program ${ }^{18}$ implemented in the Gaussian 03 program package ${ }^{19}$.

\section{RESULTS AND DISCUSSION}

The calculated quantum chemical parametres such as chemical potential $(\mu)$, electronegativity $(\chi)$, hardness $(\eta)$ and softness $(\sigma)$ were calculated. The concepts of electronegativity $(\chi)^{20}$ and global hardness $(\eta)^{21,22}$ are given by: 


$$
\begin{gathered}
\chi=-\mu=-\left(\frac{\partial \mathrm{E}}{\partial \mathrm{N}}\right)_{\mathrm{v}(\overrightarrow{\mathrm{r}})}=\frac{1}{2}\left(\frac{\partial \mu}{\partial \mathrm{N}}\right)_{v(\overrightarrow{\mathrm{r}})} \\
\eta=\frac{1}{2}\left(\frac{\partial^{2} \mathrm{E}}{\partial \mathrm{N}^{2}}\right)_{\mathrm{v}(\overrightarrow{\mathrm{r}})}
\end{gathered}
$$

where $\mu$ is the chemical potential, $\mathrm{E}$ is the total energy, $\mathrm{N}$ is the number of electrons and $v(\vec{r})$ is the external potential of the system.

The global hardness $(\eta)$ and chemical potential $(\mu)$ were calculated in terms of $\mathrm{E}_{\mathrm{HOMO}}$ and $\mathrm{E}_{\mathrm{LUMO}}{ }^{23}$ as:

$$
\mu=\frac{\mathrm{E}_{\mathrm{HOMO}}+\mathrm{E}_{\mathrm{LUMO}}}{2} ; \quad \eta=\frac{\mathrm{E}_{\mathrm{HOMO}}-\mathrm{E}_{\mathrm{LUMO}}}{2}
$$

The inverse of the global hardness is designated as the softness, $\sigma$ as follows:

$$
\sigma=1 / \eta
$$

The fraction of electrons transferred $(\Delta \mathrm{N})$ from the inhibitor molecule to the metallic atom was calculated according to Pearson ${ }^{24-26}$. For a reaction of two systems with different electronegativities (as a metallic surface and an inhibitor molecule) the following mechanism will take place: the electronic flow will occur from the molecule with lower electronegativity toward that of a higher value, until the chemical potentials are the same. In order to calculate the transferred electrons fraction, a theorical value for the electronegativity of bulk iron was used $\chi_{\mathrm{Fe}} \Psi / \leftarrow 7 \mathrm{eV}^{24,26}$ and a global hardness of $\eta_{\mathrm{Fe}}$ : 0 , by assuming that for a metallic bulk $\mathrm{I}: \mathrm{A}^{27}$ because they are softer than the neutral metallic atoms. For the calculation the following formula was used ${ }^{24,26,28}$ :

$$
\Delta \mathrm{N}=\frac{\chi_{\mathrm{Fe}}-\chi_{\text {inh }}}{2\left(\eta_{\mathrm{Fe}}+\eta_{\text {inh }}\right)}
$$

The molecular dipole polarizability $\alpha$ is the linear response of a molecular electronic distribution to the action of an external electric field. In this paper, we are presenting values of mean polarizability $(\alpha)$ as defined in the following equation:

$$
\langle\alpha\rangle=\frac{1}{3}\left(\alpha_{\mathrm{xx}}+\alpha_{\mathrm{yy}}+\alpha_{\mathrm{zz}}\right)
$$

and sometimes the anisotropy $(\Delta \alpha)$, which is written here in an obvious notation $\mathrm{as}^{29}$.

$$
\Delta \alpha=\left\{\frac{\left(\alpha_{x x}-\alpha_{y y}\right)^{2}+\left(\alpha_{x x}-\alpha_{z z}\right)^{2}+\left(\alpha_{z z}-\alpha_{y y}\right)^{2}+6\left(\alpha_{x y}^{2}+\alpha_{x z}^{2}+\alpha_{y z}^{2}\right)}{2}\right\}^{1 / 2}
$$

The $\alpha$ components of the GAUSSIAN 03W output are reported in atomic units, thus the calculated values have to be converted into electrostatic units $\left(\alpha \text { : 1a.u. }=0.1482 \times 10^{-24} \mathrm{esu}\right)^{30}$.

Isoxazoline and isoxazolidine derivatives are bearing three or more of $\mathrm{N}, \mathrm{O}, \mathrm{S}$ heteroatoms and one or two aromatic rings. The compounds are being adsorbed over these heteroatoms and aromatic rings with their $\pi$ electrons by the metal surface prevent destructive effect of aggressive acidic medium. As known, besides being structures of these heteroatoms, $\pi$ electrons available in the various functional groups can also facilitate adsorption of corrosion inhibitors to the metal surface and increase inhibition efficiencies ${ }^{16}$.

The corrosion efficiencies of inhibitors can be related to their spatial molecular structures and their molecular electronic structures. Adsorption on the metal surface depends on the structure and the chemical properties of inhibitors. The inhibitor layer has been related to the electronic structure of the molecule. The change and orientation of the inhibitor molecule at the metal surface are also important. Molecular modeling and frontier orbital theory has been proven to help in predicting the adsorption centre of the inhibitors such as the heteroatoms ( $\mathrm{S}, \mathrm{P}, \mathrm{N}$ and $\mathrm{O}$ ), the functions group and electronic density at the donor or acceptor atom $\pi$ orbital character ${ }^{31}$. In addition to, the planarity and the lonely electron pairs in the heteroatoms are important features that determine the adsorption of these molecules on the metallic surface. Certain quantum chemical parameters that can be related to the metalinhibitor interaction namely $\mathrm{E}_{\text {номо }}, \mathrm{E}_{\mathrm{LUMO}}, \Delta \mathrm{E}=\mathrm{E}_{\mathrm{LUMO}}-\mathrm{E}_{\mathrm{HOMO}}$, $\mu, \chi, \eta, \sigma, \alpha$ and $\Delta \mathrm{N}$.

The optimized structures, HOMO and LUMO orbitals of isoxazoline and isoxazolidine derivatives are presented in Fig. 1. The spatial distribution of valence electrons is determined by the HOMO orbital, electrophilic attacks can be correlated very well with atomic sites having high density of the HOMO orbital. As can be seen from Fig. 1, the HOMO is found to reside on the benzene ring and heteroatoms for all studied corrosion inhibitors. The figure clearly reveals the information that governs electrophilic attacks on the studied inhibitors.

Table-1 present $\mathrm{E}_{\text {номо }}, \mathrm{E}_{\mathrm{Lumo}}, \Delta \mathrm{E}$, total energy and \% inhibition efficiencies for isoxazoline and isoxazolidine deri-

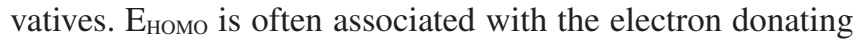
ability of a molecule. The higher the value of $\mathrm{E}_{\mathrm{Hомо}}$ of the inhibitor, the greater is the ease of offering electrons to the unoccupied d orbital of metallic iron and the higher is the inhibition efficiency of the inhibitors. $\mathrm{E}_{\text {Lumo }}$ is lower the value of energy of lowest unoccupied molecular orbital, the easier is the acceptance of electrons from metallic iron surface. Thus higher $\mathrm{E}_{\text {Номо }}$ and the lower $\mathrm{E}_{\mathrm{LUMO}}$ values generally enhance the inhibition efficiency. Moreover, smaller value of $\Delta \mathrm{E}$ for an inhibitor, higher the inhibition efficiency of that inhibitor ${ }^{32}$. The calculated $\mathrm{E}_{\text {номо, }} \mathrm{E}_{\mathrm{Lumo}}$ and $\mathrm{E}_{\text {Luмо-номо values for all }}$ molecules show that any attempt to correlate parameters with experimental inhibition efficiencies is not significant and there is no simple relation with the inhibition performance of these inhibitors.

Two types of adsorptions are known as physical and chemical adsorption. It can be concluded from the negative sign of the $\mathrm{E}_{\text {номо }}$ obtain in this study that the adsorption these isoxazoline and isoxazolidine derivatives on the steel surface is not by chemical adsorption but by physical adsorption. Physical adsorption results from electrostatic interaction between the charged centres of inhibitor and charged metal surface which results in a dipole interaction of molecules and metal surface ${ }^{33}$.

The shape, size, orientation and electronic charge on the molecule determine the degree of adsorption and the effectiveness of the inhibitor. Generally, the inhibition efficiency increases at the molecular weight of the molecules due to the increase of the contact area between corrosion inhibitor molecules and surface. As seen from Table-2, the molecular weights of PINEE and DPINEE are highest of the isoxazoline and isoxazolidine derivatives, respectively, so these molecules are expected the best inhibitors in the isoxazoline and isoxazolidine 


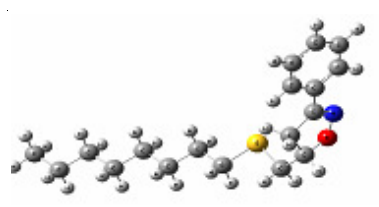

OSPI

HOMO

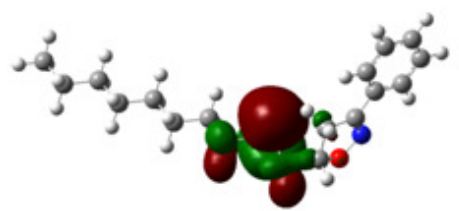

LUMO

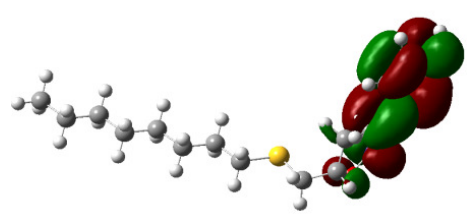

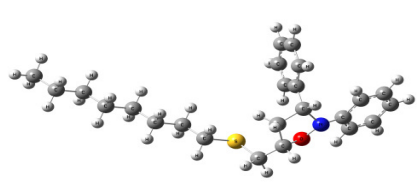

OSDPI

HOMO

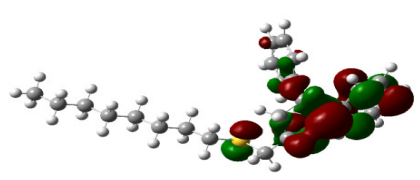

LUMO

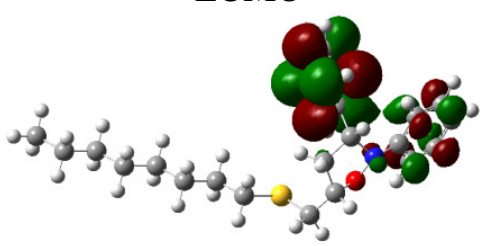

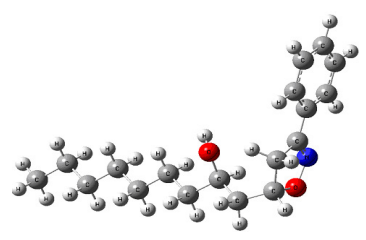

PINO

HOMO

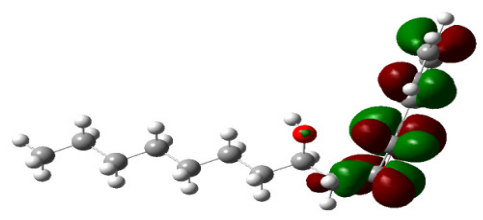

LUMO

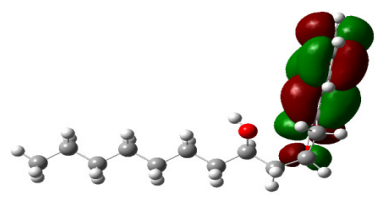

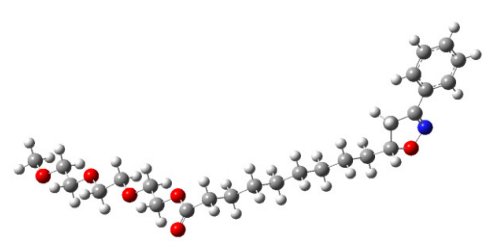

PINEE

HOMO

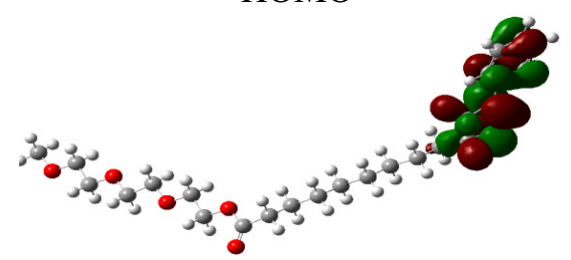

LUMO

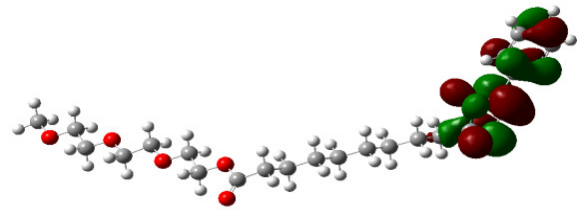

DPINO

HOMO

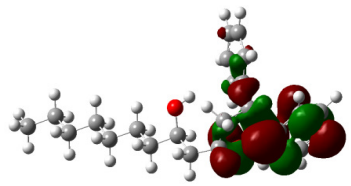

LUMO

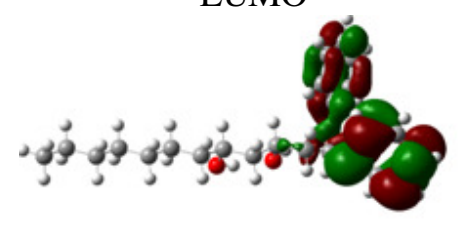

\section{LUMO}

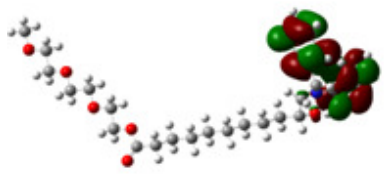

Fig. 1. Molecular structures and HOMO-LUMO of, 5-octylsulfanylmethyl-3-phenyl-4,5-dihydro-isoxazol (OSPI),1-(3-phenyl-4,5-dihydro-isoxazol-5-yl)nonan-2-ol (PINO) 9-(3-phenyl-4,5-dihydro-isoxazol-5-yl)-nonanoic acid 2-[2-(methoxy-ethoxy)-ethoxy]-ethyl ester (PINEE), 5-octylsulfanylmethyl2,3-diphenyli soxazolidine (OSDPI), 1-(2,3-diphenyl-isoxazolidin-5-yl)-nonan-2-ol (DPINO) 9-(2,3-diphenyl isoxazolidin-5-yl)-nonanoic acid 2[2-(2-methoxy-ethoxy)-ethoxy]-ethyl ester (DPINEE)

derivatives. However, they have polar ester groups, so they haven't parallel adsorption and theirs inhibition efficiencies is lower than expected inhibition efficiencies.

PINO and DPINO have same alkyl side chain, but DPINO have second benzene ring in other word a $\pi$ electron system. A result of this, inhibition efficiency of DPINO is higher than inhibition efficiency of PINO. The HOMO level is mostly localized on the benzene moiety and $\mathrm{O}$ and $\mathrm{N}$ atoms in the five membered ring and $\mathrm{OH}$ group indicating that preferred sites for electrophilic attack at metal surface are through the $\mathrm{O}$ atom (Fig. 1). This means that the benzene moiety with high coefficients of HOMO density was oriented toward the metal surface, so adsorption is probably occurred through the $\pi$ electrons of benzene moiety, the lone pairs of $\mathrm{O}$ and $\mathrm{N}$ atoms 


\begin{tabular}{|c|c|c|c|c|c|c|c|}
\hline $\begin{array}{r}\text { CALCL } \\
\text { INHIBITIO }\end{array}$ & $\begin{array}{l}\text { ED ENERGY } \\
\text { FICIENCIES }\end{array}$ & $\begin{array}{l}\text { ELS OF TH } \\
\text { ppm CONC }\end{array}$ & $\begin{array}{r}\text { TAE } \\
, \mathrm{E}_{\mathrm{LUMO}}, \Delta \mathrm{E} \\
\text { ATION OF}\end{array}$ & IO TOTAL & $\begin{array}{l}\text { GIES AND } \\
\text { OR THE S }\end{array}$ & $\begin{array}{l}\text { MEASUREI } \\
\text { OF STUDII }\end{array}$ & $\begin{array}{l}\text { RAGE } \\
\text { LECULES }\end{array}$ \\
\hline Molecules & & OSPI & PINO & PINEE & OSDPI & DPINO & DPINEE \\
\hline B3LYP & $\mathrm{E}_{\text {номо }}$ & -5.893 & -5.798 & -5.892 & -5.064 & -5.172 & -5.264 \\
\hline 6-31G(d.p) & $\mathrm{E}_{\text {LUмо }}$ & -1.041 & -0.967 & -1.072 & -0.094 & -0.367 & -0.194 \\
\hline & $\Delta \mathrm{E}$ & 4.852 & 4.831 & 4.820 & 4.970 & 4.806 & 5.070 \\
\hline & Total Energy & -33479.4 & -24691 & -40333.5 & -39799.3 & -31010.9 & -46653.4 \\
\hline $\mathrm{HF}$ & $\mathrm{E}_{\text {номо }}$ & -8.554 & -8.485 & -8.577 & -7.717 & -7.800 & -8.034 \\
\hline 6-31G(d.p) & $\mathrm{E}_{\mathrm{LUM}}$ & 2.875 & 2.939 & 2.831 & 3.802 & 3.643 & 3.727 \\
\hline & $\Delta \mathrm{E}$ & 11.429 & 11.424 & 11.408 & 11.520 & 11.443 & 11.761 \\
\hline & Total Energy & -40154.39 & -24531.6 & -40083.4 & -38526.96 & -30809.42 & -46361.17 \\
\hline Inhibition ef & $\%^{[a]} 50 \mathrm{ppm}$ & 89.3 & 56.4 & 51 & 91 & 83.9 & 88.6 \\
\hline
\end{tabular}

\section{TABLE-2}

MOLECULAR STRUCTURES, ABBREVIATIONS AND MOLECULAR WEIGHTS OF THE ISOXAZOLINE AND ISOXAZOLIDINE DERIVATIVES

\begin{tabular}{|c|c|c|c|c|}
\hline & Compounds used as inhibitors & Abbreviation & m.f. & m.w. \\
\hline 1 & $\begin{array}{l}\text { 5-octylsulfanylmethyl-3-phenyl-4,5- } \\
\text { dihydro-isoxazol }\end{array}$ & OSPI & & 305 \\
\hline 2 & $\begin{array}{l}\text { 1-(3-phenyl-4,5-dihydro-isoxazol-5- } \\
\text { yl)-nonan-2-ol }\end{array}$ & PINO & & 289 \\
\hline 3 & $\begin{array}{l}\text { 9-(3-phenyl-4,5-dihydro-isoxazol-5- } \\
\text { yl)-nonanoic acid 2-[2-(methoxy- } \\
\text { ethoxy)-ethoxy]-ethyl ester }\end{array}$ & PINEE & & 449 \\
\hline 4 & $\begin{array}{l}\text { 5-octylsulfanylmethyl-2,3-diphenyl- } \\
\text { isoxazolidine }\end{array}$ & OSDPI & & 383 \\
\hline 5 & $\begin{array}{l}\text { 1-(2,3-diphemyl-isoxazolidin-5-yl)- } \\
\text { nonan-2-ol }\end{array}$ & DPINO & & 367 \\
\hline 6 & $\begin{array}{l}\text { 9-(2,3-diphenyl-isoxazolidin-5-yl)- } \\
\text { nonanoic acid 2-[2-(2-methoxy- } \\
\text { ethoxy)-ethoxy]-ethyl ester }\end{array}$ & DPINEE & & 527 \\
\hline
\end{tabular}


TABLE-3

HARDNESS $(\eta)$, SOFTNESS $(\sigma)$, THE FRACTION OF ELECTRON TRANSFERRED $\triangle$ N FOR MOLECULES WITH INHIBITOR PROPERTIES (eV) STUDIED USING DFT AND HF METHODS WITH 6-31G(d,p) BASIS SET IN THE PRESENT WORK

\begin{tabular}{lcc|cc|cc}
\hline & \multicolumn{2}{c|}{$\eta(\mathrm{eV})$} & \multicolumn{2}{c|}{$\sigma(1 / \mathrm{eV})$} & \multicolumn{2}{c}{$\Delta \mathrm{N}$} \\
\hline Molecules & B3LYP & HF & B3LYP & HF & B3LYP & HF \\
& $6-31 \mathrm{G}(\mathrm{d}, \mathrm{p})$ & $6-31 \mathrm{G}(\mathrm{d}, \mathrm{p})$ & $6-31 \mathrm{G}(\mathrm{d}, \mathrm{p})$ & $6-31 \mathrm{G}(\mathrm{d}, \mathrm{p})$ & $6-31 \mathrm{G}(\mathrm{d}, \mathrm{p})$ & $6-31 \mathrm{G}(\mathrm{d}, \mathrm{p})$ \\
\hline OSPI & 2.426 & 5.715 & 0.412 & 0.175 & 0.728 & 0.374 \\
PINO & 2.416 & 5.712 & 0.414 & 0.175 & 0.749 & 0.370 \\
PINEE & 2.410 & 5.704 & 0.415 & 0.175 & 0.730 & 0.362 \\
OSDPI & 2.485 & 5.760 & 0.402 & 0.174 & 0.889 & 0.438 \\
DPINO & 2.403 & 5.721 & 0.416 & 0.175 & 0.880 & 0.430 \\
DPINEE & 2.535 & 5.880 & 0.394 & 0.170 & 0.843 & 0.412 \\
\hline
\end{tabular}

TABLE-4

MEAN $(<\alpha>)$ POLARIZABILITIES, THE ANISOTROPY POLARIZABILITIES $(<\Delta \alpha>)$, THE ELECTRIC DIPOL MOMENTS $(\mu)$, THE FIRST-ORDER HYPERPOLARIZABILITIES $\left(\beta_{\text {too }}\right)$ AND THE MEASURED AVERAGE INHIBITION EFFICIENCIES ${ }^{15}$ OF THE STUDIED MOLECULES FROM DFT AND HF CALCULATIONS

\begin{tabular}{lcccccc}
\hline B3LYP/6-31G(d,p) [HF/6-31G(d,p)] & OSDPI & DPINEE & DPINO & OSPI & PINEE & PINO \\
\hline$<\alpha>\times 10^{-24} \mathrm{esu}$ & 23.53 & 34.65 & 23.83 & $-19.63(-$ & -29.79 & -18.62 \\
& $(23.68)$ & $(34.74)$ & $(24.03)$ & $19.73)$ & $(-30.10)$ & $(-18.80)$ \\
$<\Delta \alpha>$ au. & 14.85 & 61.31 & 21.25 & 3.63 & 9.8 & 2.96 \\
& $(15.44)$ & $(59.12)$ & $(20.59)$ & $(4.06)$ & $(9.79)$ & $(3.52)$ \\
Dipole moment (D) & 3.80 & 3.60 & 1.18 & 4.24 & 3.95 & 2.27 \\
& $(3.63)$ & $(4.14)$ & $(1.11)$ & $(4.45)$ & $(4.99)$ & $(2.46)$ \\
Inhib. eff. \% 50 ppm (IE \%) ${ }^{[15]} 50 \mathrm{ppm}$ & 89.3 & 56.4 & 51 & 91 & 83.9 & 88.6 \\
\hline
\end{tabular}

in the five membered ring and the lone pair of $\mathrm{O}$ atom of $\mathrm{OH}$ group $^{34}$.

The optimized structure of isoxazoline derivatives and isoxazolidine derivatives with minimum energies obtain from the calculations are given in Fig. 1. As can be seen from Fig. 1 , isoxazolidine derivatives contain second benzene ring different from isoxazoline derivatives. Hence they are more easy dispersion in acidic aqueous medium. As a result of this, the inhibitory properties of the isoxazolidine derivatives more improve than isoxazoline derivatives. The comparison orders of inhibiting efficiency (\% IE) are DPINO > PINO, OSDPI > OSPI, DPINEE $>$ PINEE $^{15}$.

The sulfur atom on alkyl side chain increases the electron density on the isoxazoline and isoxazolidine derivatives and enhances the inhibition efficiency by strengthening the adsorption interaction. Experimentally, it was found that orders of the inhibition efficiencies (\% IE): OSPI > other isoxazoline derivatives and OSDPI > other isoxazolidine derivatives. This was an expected result because of the high electron releasing effect of sulfur atom.

Absolute hardness $(\eta)$ and softness $(\sigma)$ are important properties to measure the molecular stability and reactivity. A hard molecule has a large energy gap and a soft molecule has small energy gap. Soft molecules are more reactive than hard ones because they could easily offer electrons to an acceptor. For simplest transfer of electrons, adsorption could occur at the part of the molecule where $\sigma$, which is a local property, has the highest ${ }^{35}$. However, as seen from Table-3, our investigated molecules approximately equal $\eta$ and $\sigma$ values. If $\Delta \mathrm{N}<$ 3.6 (electron), the inhibition efficiency increased electrondonating ability at the metal surface ${ }^{36}$. DPINO have electron donate group $(\mathrm{OH})$, so $\Delta \mathrm{N}$ of DPINO higher than other isoxazolidine derivative's $\Delta \mathrm{N}$. Calculated values of $\Delta \mathrm{N}$ are also shown in Table-3.
The dipole moment $(\mu)$ is another indicator of the electronic distribution in a molecule and is one of the properties used to discuss and to rationalize the structure ${ }^{37}$. All the calculated values of dipole moment $(\mu)$ and polarizability $\langle\alpha\rangle$ are presented in Table-4. Comparison of the result obtained from quantum chemical calculations with experimental inhibition efficiencies indicated that the \% inhibition efficiency of the inhibitors increase with increasing value of the dipole moment. Highest value of $\mu$ using B3LYP/6-31G(d,p) method is shown for OSDPI (3.80D) which has the highest inhibition efficiency for isoxazolidine derivatives. Similarly OSPI (4.24D) has the highest inhibition efficiency and highest value of $\mu$ in for isoxazoline derivatives. Furthermore, no reasonably good correlation was obtained between polarizability, $\alpha$ and $\%$ inhibition efficiency.

Mulliken population analysis ${ }^{38}$ is mostly used for the calculation of the charge distribution in a molecule. These numerical quantities are easy to obtain and they provide at least a qualitative understanding of the structure and reactivity of molecules. The atomic charges of the studied molecules obtained by Mulliken's population analysis are shown in Table5. These charges indicate that there is more than one active centre and it is confirmed that the more negative the atomic partial charges of the adsorbed centre is, the more easily the atoms donate its electrons to the unoccupied $d$-orbital of the metal $^{39-41}$. Recently, good corrosion inhibitors are generally organic compounds which not only offer electrons to unoccupied orbital of the metal but also accept free electrons from the metal ${ }^{42}$. Frontier Orbital Prediction, the site of highest negative density is mainly the site of electrophilic attack. The more negative atomic charges of the adsorbed centers have, the more easily the electrostatic attraction between the surface and studied molecules ${ }^{43}$. O 20 atom has the most negative charge for DPINO and PINO. Thus the bond with the chelate from 
TABLE-5

CHARGES OF C, N, O, S ATOMS FOR STUDIED MOLECULES BY USING B3LYP/6-31G(d,p) AND HF/6-31G(d,p) METHODS

\begin{tabular}{|c|c|c|c|c|c|c|c|c|c|c|c|c|c|}
\hline Atoms & \multicolumn{3}{|c|}{ B3LYP/6-31G(d,p) } & \multicolumn{3}{|c|}{$\mathrm{HF} / 6-31 \mathrm{G}(\mathrm{d}, \mathrm{p})$} & \multirow[t]{2}{*}{ Atoms } & \multicolumn{3}{|c|}{ B3LYP/6-31G(d,p) } & \multicolumn{3}{|c|}{$\mathrm{HF} / 6-31 \mathrm{G}(\mathrm{d}, \mathrm{p})$} \\
\hline & OSDPI & DPINEE & DPINO & OSDPI & DPINEE & DPINO & & OSPI & PINEE & PINO & OSPI & PINEE & PINO \\
\hline $\mathrm{C} 1$ & -0.089 & -0.085 & -0.089 & -0.170 & -0.161 & -0.172 & - & - & - & - & - & - & - \\
\hline $\mathrm{C} 2$ & -0.097 & -0.104 & -0.094 & -0.137 & -0.148 & -0.137 & - & - & - & - & - & - & - \\
\hline $\mathrm{C} 3$ & -0.095 & -0.097 & -0.097 & -0.138 & -0.146 & -0.135 & - & - & - & - & - & - & - \\
\hline $\mathrm{C} 4$ & -0.109 & -0.093 & -0.109 & -0.170 & -0.138 & -0.174 & - & - & - & - & - & - & - \\
\hline C5 & -0.102 & -0.109 & -0.112 & -0.163 & -0.173 & -0.174 & - & - & - & - & - & - & - \\
\hline C6 & 0.292 & 0.280 & 0.287 & 0.293 & 0.284 & 0.291 & - & - & - & - & - & - & - \\
\hline N7 & -0.308 & -0.320 & -0.301 & -0.381 & -0.390 & -0.376 & N7 & -0.189 & -0.190 & -0.202 & -0.147 & -0.147 & -0.166 \\
\hline $\mathrm{C} 8$ & 0.020 & -0.419 & -0.429 & 0.094 & 0.105 & 0.097 & C8 & 0.244 & 0.232 & 0.244 & 0.262 & 0.248 & 0.273 \\
\hline C9 & -0.244 & -0.238 & -0.251 & 0.289 & 0.135 & -0.294 & C9 & -0.284 & -0.283 & -0.283 & -0.315 & -0.306 & -0.302 \\
\hline $\mathrm{C} 10$ & 0.237 & 0.200 & 0.219 & 0.269 & 0.252 & 0.254 & $\mathrm{C} 10$ & 0.170 & 0.187 & 0.156 & 0.218 & 0.247 & 0.203 \\
\hline O11 & -0.409 & -0.419 & -0.429 & -0.524 & -0.540 & -0.543 & O11 & -0.394 & -0.410 & -0.405 & -0.523 & -0.543 & -0.535 \\
\hline $\mathrm{C} 12$ & 0.123 & 0.093 & 0.132 & -0.020 & -0.042 & -0.014 & $\mathrm{C} 12$ & 0.109 & 0.111 & 0.105 & -0.038 & -0.036 & -0.044 \\
\hline $\mathrm{C} 13$ & -0.130 & -0.121 & -0.122 & -0.163 & -0.157 & -0.157 & $\mathrm{C} 13$ & -0.107 & -0.108 & -0.110 & -0.122 & -0.123 & -0.125 \\
\hline C14 & -0.086 & -0.088 & -0.083 & -0.136 & -0.145 & -0.140 & C14 & -0.091 & -0.091 & -0.092 & -0.155 & -0.154 & -0.155 \\
\hline C15 & -0.085 & -0.084 & -0.083 & -0.149 & -0.153 & -0.153 & C15 & -0.088 & -0.081 & -0.082 & -0.143 & -0.143 & -0.144 \\
\hline $\mathrm{C} 16$ & -0.085 & -0.087 & -0.082 & -0.146 & -0.145 & -0.144 & $\mathrm{C} 16$ & -0.091 & -0.091 & -0.092 & -0.153 & -0.153 & -0.154 \\
\hline $\mathrm{C} 17$ & -0.088 & -0.108 & -0.169 & -0.151 & -0.137 & -0.188 & C17 & -0.136 & -0.138 & -0.136 & -0.157 & -0.159 & -0.154 \\
\hline C18 & -0.377 & -0.182 & -0.206 & -0.412 & -0.219 & -0.237 & C18 & -0.331 & -0.187 & -0.179 & -0.383 & -0.227 & -0.217 \\
\hline S19 & 0.099 & - & - & 0.135 & - & - & S19 & 0.102 & - & - & 0.146 & - & - \\
\hline $\mathrm{O} 20$ & - & - & -0.554 & - & - & -0.666 & $\mathrm{O} 20$ & - & - & -0.553 & - & - & -0.666 \\
\hline
\end{tabular}

O20 [-0.554 for B3LYP/6-31G(d,p), -0.666 for HF/6-31G(d,p) DPINO and -0.553 for B3LYP/6-31G(d,p),-0.666 for HF/6$31 \mathrm{G}(\mathrm{d}, \mathrm{p}) \mathrm{PINO}$ ] will be easily formed, rather than other atoms. The calculation shows that N7, C9, O11 and C18 are high negative charges for isoxazoline and isoxazolidine derivatives. Hence these atoms are the most probable centres of adsorption via the lone pair electrons in studied molecules. The sulphur atom present positive charges, being the further value of 0.102 for B3LYP/6-31G(d,p), 0.146 for HF/6-31G(d,p) for the sulphur atom of OSPI, thus probably experiencing the greater repulsive effect towards metallic atom when the molecule acts as a nucleophile and the less value of the positive charge being 0.099 for B3LYP/6-31G(d,p), 0.135 for HF/6$31 \mathrm{G}(\mathrm{d}, \mathrm{p})$ for the sulphur atom of OSDPI. This makes the OSDPI to probably experience the greatest attractive effect towards metallic atoms when molecule acts as a nucleophile thus making it to probably exhibit the highest inhibitive effect. Similar observation has been reported by Obot et al $^{44}$ on their study of hard \& soft acid base descriptors of thiadiazole derivatives calculated by DFT: possible relationship as mild steel corrosion inhibitors.

\section{Conclusion}

The comparison between the quantum chemical parameters of isoxazoline and isoxazolidine derivatives was calculated using the density functional theory (DFT) and $a b$ initio (HF) methods. The quantum chemical parameters of six different molecules indicate that the inhibition effect of isoxazoline and isoxazolidine derivatives is no simple relation with the inhibition performance of these inhibitors. The inhibition efficiency increased with the increase in dipole moment and $\Delta \mathrm{N}$. Isoxazolidine derivatives have second benzene ring in other word a $\pi$ electron system. A result of this, inhibition efficiency of isoxazolidine is higher than inhibition efficiency of isoxazoline.
Mulliken population analysis shows, that the mechanism of adsorption between the isoxazoline and isoxazolidine derivatives and mild steel surface occurs mainly through the same atoms (N7, C9, O11, C18) not the sulphur atom.

\section{REFERENCES}

1. S.B. Jadhav, R.A. Shastri, K.V. Gaikwad and S.V. Gaikwad, E.-J. Chem., 6(S1), 183 (2009).

2. T. Shah and V. Desai, J. Serb. Chem. Soc., 72, 443 (2007).

3. M.B. Gravestock, N.J. Hales, M.L. Swain, S.I. Hauck and S.D. Mills. Oxazolidinone and/or Isoxazoline as Antibacterial Agents, US Patent, 7,396,847 (2008).

4. P.C. Sharma, S.V. Sharma, S. Jain, D. Singh and B. Suresh, Acta Pol. Pharm., 66, 101 (2009).

5. M. Imran and S.A. Khan, Indian J. Heterocycl. Chem., 13, 213 (2004).

6. P. Zhang, C. Wei, E. Wang, W. Wang, M. Liu, Q. Yin, H. Chen, K. Wang, X. Li and J. Zhang, Carbohydr. Res., 351, 7 (2012).

7. P.V. Tekade, K.N. Patil and P.S. Bodkhe, Asian J. Chem., 17, 1340 (2005).

8. B. Loh, L. Vozzolo, B.J. Mok, C.C. Lee, R.J. Fitzmaurice, S. Caddick and A. Fassati, Chem. Biol. Drug Des., 75, 461 (2010).

9. H. Shinkai, S. Onogi, M. Tanka, T. Shibata, M. Iwao, K. Wakitani and I. Uchida, J. Med. Chem., 41, 1927 (1998).

10. M.P. Sadashiva, A. Nataraju, H. MalleshA, B.S. Vishwanath and K.S. Rangappa, Int. J. Mol. Med., 16, 895 (2005).

11. R.V. Kumar, S. Mukherjee, P. A.K. Prasad, C.E. Olsen, S.J.C. Schaffer, S.K. Sharma, A.C. Watterson, W. Errington and V.S. Parmar, Tedrahedron, 61, 5687 (2005).

12. R. Singh, S.D. Bhella, A.K. Sexana, M. Shanmugavel, A. Faruk and M.P.S. Ishar, Tedrahedron, 63, 2283 (2007).

13. S.A. Ali, A.M. El-Shareef, R.F. Al-Ghamdi and M.T. Saeed, Corros. Sci., 47, 2659 (2005).

14. S.A. Ali, M.T. Saeed and S.U. Rahman, Corros. Sci., 45, 253 (2003).

15. A. Yildirim and M. Çetin, Corros. Sci., 50, 155 (2008).

16. Y.S. Kara, S.G. Sagdinc and A. Esme, Prot. Met. Phys. Chem. Surf., 48, 710 (2012).

17. HyperChem 7.5 Release for Windows, Hypercube Inc., USA, (2003).

18. A. Frisch, A.B. Nielsen and A.J. Holder, Gauss View Users Manual, Gaussian Inc., Pittsburg (2000).

19. M.J. Frisch, G.W. Trucks, H.B. Schlegel, G.E. Scuseria, M.A. Robb, J.R. Cheeseman, J.A. Montgomery, T. Vreven, K.N. Kudin, J.C. Burant, J.M. Millam, S.S. Iyengar, J. Tomasi, V. Barone, B. Mennucci, M. Cossi, 
G. Scalmani, N. Rega, G.A. Petersson, H. Nakatsuji, M.M. Ehara, K. Toyota, R. Fukuda, J. Hasegawa, M. Ishida, T. Nakajima, Y. Honda, O. Kitao, H. Nakai, M. Klene, X. Li, J.E. Knox, H.P. Hratchian, J.B. Cross, V. Bakken, C. Adamo, J. Jaramillo, R. Gomperts, R.E. Stratmann, O. Yazyev, A.J. Austin, R. Cammi, C. Pomelli, J.W. Ochterski, P.Y. Ayala, K. Morokuma, G.A. Voth, P. Salvador, J.J. Dannenberg, V.G. Zakrzewski, S. Dapprich, A.D. Daniels, M.C. Strain, O. Farkas, D.K. Malick, A.D. Rabuck, K. Raghavachari, J.B. Foresman, J.V. Ortiz, Q. Cui, A.G. Baboul, S. Clifford, J. Cioslowski, B.B. Stefanov, G. Liu, A. Liashenko, P. Piskorz, I. Komaromi, R.L. Martin, D.J. Fox, T. Keith, M.A. Al-Laham, C.Y. Peng, A. Nanayakkara, M. Challacombe, P.M. W. Gill, B. Johnson, W. Chen, M.W. Wong, C. Gonzalez, J.A. Pople, Gaussian 03, Revision B.05, Gaussian, Inc., Wallingford, CT (2004).

20. R.G. Parr, D.A. Donnely, M. Levy and M. Palke, J. Chem. Phys., 68, 3801 (1978).

21. R.G. Parr and R.G. Pearson, J. Am. Chem. Soc., 105, 7512 (1983).

22. R.G. Pearson, Inorg. Chem., 27, 734 (1998).

23. B. Gomez, N.V. Likhanova, M.A. Dominguez-Aguilar, R. MartinezPalou, A. Vela and J.L. Gazquez, J. Chem. Phys., B110, 8928 (2006).

24. V.S. Sasti and J.R. Perumareddi, Corrosion, 53, 617 (1997).

25. I. Lukovits, E. Kalman and F. Zucchi, Corrosion, 57, 3 (2001).

26. S. Martinez, Mater. Chem. Phys., 77, 97 (2002).

27. M.J.S. Dewar and W. Thiel, J. Am. Chem. Soc., 99, 4899 (1977).
28. L.M. Rodriguez-Valdez, W. Villamisar, M. Casales, J.G. GonzalezRodriguez, A. Martinez-Villafane, L. Martinez and D. GlossmanMitnik, Corros. Sci., 48, 4053 (2006).

29. G.J. Avila, J. Chem. Phys., 122, 144310 (2005).

30. A.B. Ahmed, H. Feki, Y. Abid, H. Boughzala and A. Mlayah, J. Mol. Struct., 888, 180 (2008).

31. N.O. Eddy and E.E. Ebenso, Int. J. Electrochem. Sci., 5, 731 (2010).

32. I. Ahamad, R. Prasad and M.A. Quraishi, Corros. Sci., 52, 933 (2010).

33. T. Arslan, F. Kandemirli, E.E. Ebenso, I. Love and H. Alemu, Corros. Sci., 51, 35 (2009).

34. M.S. Masoud, M.K. Awad, M.A. Shaker and M.M.T. El-Tahawy, Corros. Sci., 52, 2387 (2010).

35. S. Martinez, Mater. Chem. Phys., 77, 97 (2002).

36. H. Ju, Z.-P. Kai and Y. Li, Corros. Sci., 50, 865 (2008).

37. O. Kikuchi, Quant. Struct.-Act. Relat., 6, 179 (1987).

38. R.S. Mulliken, J. Chem. Phys., 23, 1833 (1955).

39. K.F. Khaled, Electrochim. Acta, 53, 3484 (2008).

40. K.F. Khaled and M.A. Amin, J. Appl. Electrochem., 38, 1609 (2008).

41. J.M. Roque, T. Pandiyan, J. Cruz and E.Gracia-Ochoa, Corros. Sci., 50, 614 (2008).

42. E.E. Ebenso, T. Arslan, F. Kandemirli, I. Love, C. Ögretir, M. Saracoglu and S.A. Umoren, Int. J. Quantum. Chem., 110, 2614 (2010).

43. G. Gece, S. Bilgiç and Ö. Türksen, Mater. Corros., 61, 141 (2010).

44. I.B. Obot and N.O. Obi-Egbedi, Der Pharma Chem., 1, 151 (2009). 